\title{
Amor, riesgo y Sida: hombres que tienen sexo con hombres
}

\author{
Isabel Cristina Posada Zapata' (iD 0000-0003-4953-6490 \\ Carlos Enrique Yepes Delgado' 0000-0001-5656-4989 \\ Lina Marcela Patiño Olarte' $0000-0002-4176-9575$ \\ 'Universidad de Antioquia, Medellín, Antioquia, Colombia. 050001.
}

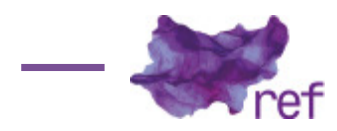

Resumen: Se buscó comprender las condiciones en las cuales los hombres que tienen sexo con hombres se arriesgan a contraer el virus que produce el SIDA, en investigación de enfoque cualitativo con teoría fundada, a partir de entrevistas a hombres con relaciones homosexuales y conocimientos sobre el SIDA. Se encontró la homosexualidad como conducta reprochable, cuyo castigo es adquirir el virus que produce el SIDA. El conocimiento sobre la enfermedad no produce la evitación de las conductas de riesgo; pues, al buscar relacionarse con otro, se asume el riesgo. Se concluye que la unión de las carencias afectivas y la discriminación propicia una sobrevaloración de los encuentros de pareja; el afecto allí vivido se equipara al reconocimiento de un ser humano que es legitimado por otro. Palabras clave: homosexualidad; síndrome de inmunodeficiencia adquirida; riesgo; afecto.

Amor, Risco e Alds: homens que fazem sexo com homens

Resumo: Buscou-se compreender as condições em que os homens que têm sexo com homens se arriscam a contrair o vírus que causa a AIDS, numa pesquisa de enfoque qualitativo, baseada na teoria fundamentada, a partir de entrevistas com homens homossexuais com conhecimento sobre AIDS. Encontramos que a homossexualidade é uma conduta reprovável, cujo castigo é adquirir o vírus que causa a AIDS. O conhecimento sobre a doença não causa prevenção de comportamentos de risco; porque, quando se busca a relação com o outro, assume-se o risco. Conclui-se que a união das carências afetivas e a discriminação promove uma sobrevalorização dos encontros de casais; o afeto ali vivido equivale ao reconhecimento de um ser humano que é legitimado por outro.

Palavras-Chave: homossexualidade; síndrome de imunodeficiência adquirida; risco; afeto.

Love, risk and AIDS: men who have sex with men

Abstract: The aim of this work is to understand the conditions under which men take risk of contracting the virus that causes AIDS. It is a qualitative research, based on the Grounded Theory, with interviews with men who have sex with other men. The results show homosexuality as an improper conduct, for which the punishment is AIDS. The knowledge about the disease does not prevent risky behaviors; because, when looking for a relationship with the other, they are accepting the risk. The study concludes that the union of lack of affection and discrimination promotes an overvaluation of the couple encounters. The affection lived in that situation is equated to the recognition of a human being who is legitimated by another human being.

Keywords: Homosexuality; Acquired immunodeficiency syndrome; Risk; Affect.

\section{Introducción}

Uno de los graves problemas para la salud pública a nivel mundial ha sido el fenómeno de la afectación por el virus que produce el SIDA, pues si bien las muertes asociadas a la enfermedad han disminuido, y la cobertura de tratamiento en cifras globales ha aumentado drásticamente, no se ha podido impactar de la forma esperada la tasa de nuevas infecciones, que ha ido decreciendo, pero no lo de la manera esperada por los expertos, presentándose 1,8 millones de nuevos casos 
para el 2017 (UNAIDS, 2018). El VIH/Sida ha rebasado el campo biológico, pues sus implicaciones han comprometido la dimensión social, económica y cultural de aquellas personas que han padecido esta enfermedad. Algunos aspectos socioculturales relacionados con el fenómeno son la connotación moral asociada a la enfermedad, el señalamiento, la culpabilización, el rechazo, el miedo, el aislamiento y la alteración de la funcionalidad familiar.

En Latinoamérica, una de las poblaciones más afectadas por el Sida, aportando para el 2017 el $41 \%$ de las nuevas infecciones (UNAIDS, 2018), son los varones que tienen sexo con hombres (HSH), término acuñado por algunos epidemiólogos para nombrar aquellos varones que, cualquiera sea su identidad sexual - homosexuales, heterosexuales, bisexuales -, tienen relaciones sexuales con varones) (Organización Panamericana de la Salud; Organización Mundial de la Salud; ONUSIDA, 2001 , p. 3), y que contribuyen en gran medida al crecimiento acelerado de las cifras, situación que se complejiza al multiplicar cada caso notificado por otros que aún no han sido diagnosticados.

Colombia no es ajena a esta situación, pues en el país se ha reconocido cómo el grupo de HSH mantiene conductas de riesgo que los expone a una mayor probabilidad de contraer la infección por el virus de la inmunodeficiencia humana VIH (ONUSIDA, 1999, p. 24; MINISTERIO DE LA PROTECCIÓN SOCIAL, 2010), conductas que posiblemente se liguen a condiciones críticas de señalamiento, rechazo social y familiar, como también a la clandestinidad obligada en la que desarrollan sus encuentros de pareja. Según el Sistema Nacional de Vigilancia en Salud Pública ( SIVIGILA), desde 1985 hasta el 31 de diciembre del año 2013 se notificaron 92.379 casos de infección por VIH. Entre 2008 y 2013 la notificación de casos tendió al incremento, cerrando el último año con 8.208 casos (MINISTERIO DE LA PROTECCIÓN SOCIAL, 2013).

En cuanto a la población antioqueña, se reportaron 872 casos durante el 2010 con una incidencia de 14,4/100.000 habitantes, de éstos 484 se presentaron en Medellín para una tasa de 20,7/100.000 habitantes (Dirección Seccional de Antioquia, 2011).

Frente a este alarmante aumento y con el objetivo de conocer por qué se infectaba la población, se desarrolló en la ciudad una investigación microetnográfica que intentaba comprender el significado de algunas de las vivencias que, frente a la epidemia del virus que produce el SIDA, experimentaban los grupos expuestos a un mayor riesgo de infección o enfermedad, las cuales pudieran explicar el éxito o el fracaso de los programas de intervención en la región (Servicio Seccional de Salud de Antioquia, 1993).

Las campañas publicitarias de prevención y autocuidado no han respondido al comportamiento de la enfermedad, ya que algunos estudios demuestran que se han focalizado en la información y no en las necesidades específicas de cada grupo poblacional (ONUSIDA, 1999; Elizabeth PISANI; Tim BROWN; Tobi SAIDEL; Thomas REHLE; Michel CARAËL, 2002). Además de ello - revisiones presentadas para Latinoamérica por la Organización Panamericana de la Salud establecen que no se sistematizan los resultados de estas intervenciones, así como tampoco se involucra a la sociedad civil para disminuir la estigmatización y discriminación que potencian los comportamientos de riesgo frente al $\mathrm{VlH}$-, es especial en los grupos considerados clave como los HSH (OMS; OPS; ONUSIDA, 2017). Se ha encontrado que los conocimientos sobre la enfermedad y cómo prevenirla no necesariamente garantizan conductas de prevención, lo que pone de manifiesto que aunque es relevante que la población tenga mayor información sobre la infección, esto no garantiza que las conductas de riesgo desaparezcan; de esta forma, la información no es suficiente para desarrollar conductas dirigidas a la prevención frente al riesgo de adquirir el VIH, lo que obliga a preguntarse por qué persisten los comportamientos de riesgo en dicha población, aun teniendo información suficiente sobre la enfermedad.

En este contexto, esta investigación permitió construir una aproximación teórica consecuente con los significados vitales de los HSH como grupo poblacional, y así lograr como objetivo comprender el escenario y las dinámicas en la cuales éstos deciden asumir el riesgo de contraer el virus que produce el SIDA, aun conociendo información sobre su prevención. Esta comprensión puede contribuir en el diseño de nuevas formas de prevención y otras actitudes que estén fundamentadas en el ejercicio de escuchar y desmitificar a esta población.

\section{Materiales y métodos}

Se toma como punto de partida el enfoque cualitativo con base en la Teoría Fundada como método de investigación. El interaccionismo simbólico, como soporte teórico y fundamento de esta teoría, propone una corriente de pensamiento donde se hace énfasis en el significado de la acción afirmando que los individuos actúan sobre la sociedad: son las personas quienes actúan con base en los significados de una situación, teniendo en cuenta que estos significados y estas acciones se enmarcan en un proceso (Carmen DE LA CUESTA, 1999).

Esta teoría refuerza en sus premisas la capacidad de las personas para elegir y reflexionar: el individuo es un agente activo que encuentra significados y explicaciones y resuelve problemas.

Bajo este paradigma, se van construyendo hipótesis en la medida que se avanza con la recolección y el análisis, de tal forma que tales hipótesis puedan ser sometidas a una triangulación 
con futuros entrevistados. Lo que se presenta como resultados en la investigación es ilustrado con discursos que representan lo dicho por los entrevistados y triangulado en el proceso de análisis, es decir, un fragmento representa el sentido de varios participantes. Por esto, este planteamiento se hizo pertinente como fundamento conceptual y metodológico para encontrar respuesta a las preguntas de esta investigación.

Se definieron tres momentos de análisis, donde la tarea consistió en codificar los datos, es decir, fragmentar, conceptualizar e integrarlos para formar teorías (Juliet CORBIN; Anselm STRAUSS, 2002). El primer momento en el proceso de codificación es denominado codificación abierta, consistente en un momento explicativo donde los fenómenos interaccionan entre sí y de donde surgen categorías descriptivas. Un segundo momento es llamado codificación axial, y consiste en una reagrupación de los datos fracturados en la codificación abierta. Allí, se relacionan categorías y subcategorías analíticas que explican las condiciones y consecuencias del fenómeno, entrecruzando propiedades y dimensiones. En la codificación selectiva, como último momento del análisis de los datos, se integran y refinan las categorías analíticas, llegando a las interpretativas, para luego formar un esquema teórico mayor que da lugar a la teoría propiamente dicha (CORBIN; STRAUSS, 2002).

La estrategia de selección de los informantes fue el muestreo teórico, el cual consiste en una selección intencional de varios casos que puedan compararse y contrastarse. Estos casos se eligen por su posible relevancia para el campo teórico que se pretende estudiar (Judith GOETZ; Margaret LECOMPTE, 1988). En este orden de ideas, fueron elegidos los informantes que cumplieran con los criterios de inclusión del estudio: a) Los informantes debían tener relaciones homoeróticas (no necesariamente exclusivas) al momento de la entrevista; b) de sexo masculino; c) mayor de 18 años; y d) tener conocimientos básicos acerca del SIDA. La mayoría de los informantes tenían posiciones representativas o liderazgo dentro de sus grupos, lo que enriqueció la calidad de la información aportada, pues en su discurso no sólo refirieron sus vivencias personales, sino que pudieron dar cuenta de los fenómenos sociales relevantes para este grupo poblacional en la ciudad de Medellín.

Se entrevistaron 19 sujetos, entre los 18 y 48 años de edad, tratando de buscar representatividad de las edades de la población HSH en la ciudad de Medellín, y con previo consentimiento informado en correspondencia con los lineamientos éticos del Ministerio de Salud de Colombia (Ministerio de Salud, 1993). En las entrevistas se pudieron explorar aspectos claves relacionados con el objetivo del estudio, los cuales se reflejaron en cuatro ejes temáticos: información sobre el SIDA, afectividad y relaciones significativas, pareja y riesgo, y comportamiento del grupo de amigos. A lo largo de los discursos se observó que algunos de los participantes se nombraron a sí mismos como homosexuales o gays, denominaciones que están incluidas en la categoría HSH, entendiendo que ésta incluye desde el hombre que tiene relaciones esporádicas con otros hombres hasta el que declara abiertamente su homosexualidad.

\section{Resultados y discusión}

El siguiente gráfico permite ilustrar como se fue construyendo la teoría a partir del análisis de los discursos de los participantes. Los resultados indican que el SIDA sigue estando asociado a la

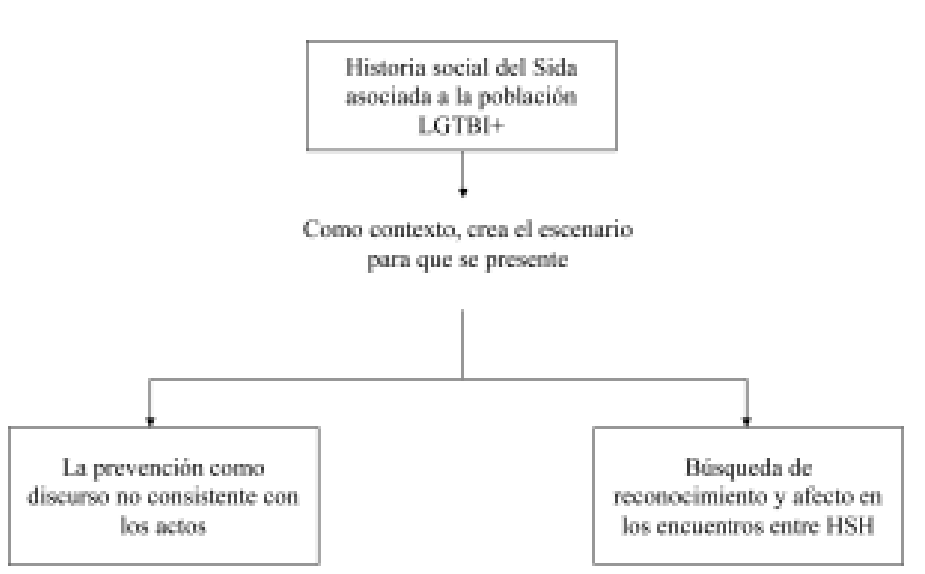
población LGBTQ + en los imaginarios sociales, lo que crea un escenario para que se presenten dos fenómenos que con-dicionan la vivencia de la relación de pareja homoerótica en condicio-nes de riesgo para ad-quirir el $\mathrm{VIH}$ : el discurso de prevención no parece transferirse a actos consecuentes, fenómeno que se une a la búsque-da constante de afecto por medio de los encuentros entre HSH.

Gráfico 1 - Ejes centrales que dan origen a la teoría fundada Fuente: elaboración del autor

\#PraTodoMundoVer El gráfico es un mapa conceptual a modo de tríada, que presenta las tres categorías resultantes de la investigación, que indica que la historia social del Sida se asocia a la población LGTBA+, formando un contexto para crear escenarios que posibilitan la prevención como discurso no consistente con los actos y la búsqueda de reconocimiento y afecto en los encuentros entre hombres que tienen sexo con hombres. 


\section{Historia social del Sida asociada a la población LGBTQ +}

Las diferentes maneras que tienen los seres humanos para relacionarse no pueden nombrarse públicamente en su totalidad. En este caso, la población LGBTQ + no ha podido establecerse socialmente como grupo aceptado; el pertenecer a este grupo significa en algunos países andinos en América del Sur discriminación, marginalidad, repudio social, prejuicio y peligro para los valores de la sociedad preestablecida. Así, muchos individuos no asumen su tendencia afectiva y erótica hacia personas de su mismo sexo, por las consecuencias sociales, así como en su salud mental, en las relaciones familiares, en su subjetividad política, en las oportunidades de desarrollo económico, entre otras que esto trae, y prefieren pensarse como hombres con encuentros episódicos con otros hombres, más no como homosexuales, de allí que las organizaciones sociales hayan adoptado el término HSH para nombrar a estos hombres (Gabriel GUAJARDO, 2002, p. 57-79).

A lo largo de la historia, varios estudios y teorías han propuesto que la homosexualidad no corresponde a la naturaleza humana, que es fruto de conductas reprochables que no concuerdan con la virtud de los hombres, y que, de esta manera, debe ser reprobable desde todo punto de vista, y aquellos que la practican deben mantener sus manifestaciones al margen de lo público (José TORO, 2002, p. 81-102).

Sin embargo, la discriminación que soportan los grupos asociados a las conductas homosexuales, como la población $\mathrm{LGBTQ}+$, no debe ser tomada como un fenómeno homogéneo, pues para su análisis ha de tenerse en cuenta la interseccionalidad necesaria para comprender las formas en las que ella se presenta. Ello implica afirmar que las violencias recibidas por personas LGBTQ + no son las mismas y que dependen también de las características particulares de las personas, que pueden empeorar incluso sus condiciones de vulnerabilidad, como por ejemplo pertenecer a una etnia indígena, estar en condición de migrante, ser pobre, sin educación o pertenecer a una raza afrodescendiente (ORGANIZACIÓN DE ESTADOS AMERICANOS, 2015).

La educación que se ha impartido y que ha sido apoyada por directrices morales e históricas vincula la noción de ser hombre con las prácticas sexuales frecuentes y con numerosas parejas, y de eso no se escapan los HSH, pues desde pequeños están sometidos a estos preceptos y a un entorno cultural que marca el significado de ser hombre. Tal vez esto pueda explicar la persistencia de conductas de promiscuidad, que, además, son punto de partida para el señalamiento como culpables en la historia del Sida. Uno de los entrevistados lo expresaba de la siguiente manera:

No es ningún secreto decir que la promiscuidad existe. Es más, siempre ha existido. Tampoco es un secreto decir que entre nosotros es mas...es más frecuente la promiscuidad. Eso es uno de los defectos que quisiera corregir el homosexual. Pero es difícil de manejar. La promiscuidad es... para mí es el punto más grave para... para ser irresponsable en cuanto al VIH. (Hombre de 34 años, deportista)

Asimismo, esta conducta asociada a los grupos LGBTQ + no solo se ha convertido en un referente de crítica, sino también en un tema tabú que a todos inquieta, atemoriza y confronta, prefiriendo colocarlo en los lugares excluidos a la mirada pública y al reconocimiento en el discurso social. Así lo afirma un joven que comparte su experiencia: "Porque ante la sociedad no somos bien vistos, y aunque ya llevamos un trecho bastante largo y ganado, el tabú sigue ahí, sigue ahí" (Hombre de 27 años, pensionado).

Sin embargo, es importante resaltar que el estigma social que genera el ser homosexual o el proclamarse como alguien de la comunidad $L G B T Q$ + no sólo crea riesgos sociales, sino también de orden afectivo, pues aún la familia, como núcleo de desarrollo psicoafectivo de cualquier individuo, cuando descubre esta posición en uno de sus miembros, llega a optar por el aislamiento y el rechazo de éste, en un intento por negar aquello que no comprende, y que, por la inmersión en la cultura, no tiene elementos para aceptar (Ricardo LLAMAS, 1998). El lugar de la familia, sin embargo, ha de considerarse parte de un análisis con enfoque interseccional, donde factores como la edad y la dependencia económica de niños y jóvenes pueden agudizar los problemas derivados por las pérdidas de afectividad positiva en la familia, a causa del rechazo de la conducta asociada a la población LGBTQ + en uno de sus miembros (OEA, 2015).

Con estos antecedentes, donde la población $L G B T Q+$ ha sido blanco de señalamientos importantes en la sociedad, apareció en 1981 una enfermedad reportada en Estados Unidos (CENTRES FOR DISEASE CONTROL, 1993), cuyos informes indicaban que los afectados eran todos varones homosexuales, con registro previo de múltiples enfermedades sexualmente transmisibles. De allí que, desde sus comienzos, la enfermedad fuera señalada como un trastorno asociado a la homosexualidad, dándole la denominación de "Deficiencia Inmunitaria relacionada con la Homosexualidad" o GRID (Gay Related Inmuno Deficiency). Así lo recordaba uno de los líderes sociales de los grupos LGBTQ + de la ciudad:

Inicialmente tuvo un impacto muy grande en la medida, en que cuando la epidemia se dio a conocer en occidente, la población afectada era, la población de hombres que tenían sexo 
con hombres, entonces eso llevó a un estigma por un lado de la población general. (Hombre de 27 años, docente)

La respuesta de la ciencia ante los síntomas de la enfermedad y las características de los enfermos fue el inicio de una nueva etapa en la culpabilización y en la persecución de los grupos $\mathrm{LGBTQ}+$, creando ante el mundo una imagen que generó miedo, haciendo que el homosexual fuera sentido como peligroso, reforzando tal estigmatización (Alfonso GARCÍA-MARTíNEZ, 2005, p. 50-57).

Esta percepción que relaciona de manera directa la homosexualidad y el Sida contiene una gran carga de señalamiento, donde la enfermedad viene a significar un castigo para una conducta desviada, que, a su vez, amenaza a quienes no la comparten (Susan SONTAG, 1989). Los entrevistados manifiestan:

Yo pienso que el Sida ha ido como asociado con la adopción sexual, cierto, entonces en una sociedad homofóbica, patriarcal, machista y heterosexista, se coincide la práctica homosexual y los HSH, y se perciben como algo perverso, entonces todo lo perverso está relacionado con el Sida, el Sida es la institución biológica, digamos de esa perversión sexual. (Hombre de 23 años, abogado)

El simbolismo que se le atribuyó a estas conductas entre HSH ha hecho que el Sida, siendo una enfermedad mortal, se diferencie de otras igualmente letales:

Entonces, me parece que a todas las enfermedades hay que ponerles atención, porque es que todas pueden matar. Pues una enfermedad mal llevada, puede ser una gripa te puede llevar a una neumonía y morirte. Entonces, todas las enfermedades hay que prevenirlas. Pero no magnificar el Sida, porque está unido a lo sexual, entonces, lo pusieron como algo muy malo, por encima de todos. (Hombre de 32 años, bacteriólogo)

El curso de la historia de esta enfermedad comenzó a cambiar cuando, en 1982, se presentaron nuevos casos en personas con características diferentes a los HSH, por ello, la denominación de la enfermedad fue Sida (Síndrome de Inmuno Deficiencia Adquirida). Esto permitió una nueva perspectiva de este fenómeno en donde el señalamiento ha tenido que ser soportado por diferentes grupos humanos, lo que es reconocido por las personas entrevistadas:

Antes se hablaba de que las personas homosexuales éramos la comunidad de más riesgo. Yo pienso que ahora, y más como persona que trabajo en una clínica, en un servicio hospitalario, me he dado cuenta que hoy en día eso no es así. (Hombre de 19 años, enfermero)

A pesar de esto, en Medellín sigue siendo difícil identificarse como integrante de la población LGBTQ+ o como homosexual y más aún nombrarse como tal públicamente; con una expresión corta pero significativa, lo manifestaba uno de los entrevistados: "Mira, si yo viviera en Ámsterdam no sería ningún problema [...] porque me parece que una cosa que muy poca gente le queda clara es que homosexuales son como flores, como fauna, hay de todo tipo" (Hombre de 25 años, estudiante).

Un punto en el que coinciden los entrevistados es que el fenómeno del Sida ha permitido que la homosexualidad y los grupos de LGBTQ + se hagan públicos, y que algunos sectores se hayan ocupado de ella, así fuera por la importancia que adquirió como grupo de riesgo, hecho que ha significado una emergencia, un avance hacia su exposición en sociedad, que, aunque se perciba peligroso por ciertos sectores sociales, evita su negación:

Hay que agradecerle mucho al Sida, para nosotros, para la población homosexual [...] que el virus, la epidemia, visibilizó lo invisible, que nos sacó a la luz pública, tristemente hemos cargado el lastre de la epidemia, pero también el mundo ha ido cambiando poco a poco la percepción que la epidemia no es de población vulnerable [...] y se va metiendo en el inconsciente que los gay existen, y ya la gente se ha dado al dolor, o sea dice sí; y las novias tienen un dicho: "los hombres de ahora el que no está dañado está ocupado", pues como para decir que definitivamente ya es un realidad, que ya si los homosexuales lo sabemos capitalizar es ganancia, ya el reto es nuestro, y esa es la razón por la que nosotros hacemos corporaciones. (Hombre de 46 años, activista gay)

De esta forma, se dimensiona que el señalamiento social que relaciona Sida y grupos $L G B T Q$ + se fundamenta en varios aspectos. En primer lugar, en la historia de los primeros casos registrados en los Estados Unidos; en segundo lugar, en el temor y el rechazo que genera en sociedad toda conducta que se halle por fuera de los parámetros establecidos; y, por último, en la misma conducta de las personas $\mathrm{LGBTQ}+$, que refuerza el señalamiento que hacen otros grupos. Este último componente, referido a lo comportamental, no pretende afirmar que otros grupos, como los heterosexuales, no mantengan a su vez conductas que también los colocan en una posición riesgosa de adquirir el virus del Sida, lo que parece manifestarse es el acento que se coloca socialmente sobre ciertos grupos señalados desde la moralidad o la normalidad consensuada, un acento que no debe olvidar la interseccionalidad de los actos de discriminación, donde, entre 
el grupo LGBTQ + señalado por su comportamiento, también hay matices, que hacen que algunos de ellos sufran mayores consecuencias en razón de sus características: se trata de trabajar la intersección para entender las desigualdades en un fenómeno que aísla a una comunidad de formas distintas entre sus miembros (Gerard COLL-PLANAS; Marta CRUELLS, 2013, p. 153-172).

\section{La prevención como discurso no consistente con los actos}

Hasta nuestros días, los HSH, así como otros grupos específicos, han obtenido información básica de la enfermedad a través de los medios de comunicación y de las campañas de educación y prevención dirigidas a otras poblaciones o a ellos mismos en sus lugares cotidianos de reunión. Pero, estos individuos siguen teniendo comportamientos de riesgo sexuales que aumentan sus probabilidades de adquirir el virus del Sida, y que de hecho contribuyen en gran proporción al aumento de las cifras de la epidemia (PROFAMILIA, 2006).

Estudios anteriores han señalado que las campañas de prevención no han producido el impacto esperado (ONUSIDA, 1999), lo cual revela que las personas continúan teniendo comportamientos de riesgo, aún con información suficiente sobre la enfermedad. Sin embargo, tales conductas no se relacionan de forma significativa o directa con la ausencia de información, es decir, las campañas han cumplido con el objetivo de informar, mas no producen en los individuos conductas generalizadas de prevención frente al VIH (ONUSIDA, 1999). Algunos estudios permiten explicar este fenómeno, pues concluyen que la prevención se ha realizado bajo diferentes modelos, pero sin tener en cuenta las necesidades de la población (John ESTRADA, 2004, p. 1 18). Un ejemplo de ello se estableció en un estudio realizado con adolescentes en la ciudad de Medellín, publicado en el año 2007, donde se pudo establecer que más del $90 \%$ de la población estudiada consideraba que el SIDA era una enfermedad grave o fatal, mientras que sus comportamientos de riesgo sexuales que los exponían a la infección se presentaban en más del 70\% de los encuestados (Stefano VINACCIA; Japcy QUICENO; Ana GAVIRIA; Ana SOTO; María GIL; Rafael BALLESTER, 2007). En estudios similares realizados con población joven en otros países andinos en América del Sur, se encuentra que más de la mitad de la población estudiada cree no correr riesgos en sus relaciones sexuales, pues se desarrollan con una pareja estable en una relación considerada fiel (Jesús CHIRINOS; OIga BARDALES; María SEGURA, 2006, p. 79-85).

Para ilustrar esta situación en una población específica, las referencias epidemiológicas de años recientes muestran que los casos de infección que involucran población homo-bisexual constituyen más de la mitad de los casos totales de nuevos infectados. Este comportamiento epidemiológico no parece cambiar y, mientras las conductas de riesgo predominen, las cifras continuarán aumentando de forma exponencial (MINISTERIO DE LA PROTECCIÓN SOCIAL, 2012).

Entre los HSH de la ciudad de Medellín predomina un discurso bien establecido y suficientemente argumentado sobre la prevención del VIH y otras infecciones de transmisión sexual, que se expone ante los otros como un esquema, y que ha sido incorporado a la vida cotidiana. Así lo exponía uno de los entrevistados: "Yo creo que prevenir así, es como cepillarse los dientes. O sea, es un acto que tenés que hacer todos los días, pensando que lo tenés que hacer por prevenir algo. Uno previene la caries, así puede prevenir el VIH" (Hombre de 32 años, bacteriólogo).

En la actualidad, se han conformado en la ciudad grupos de trabajo que han defendido de forma enérgica el mantenimiento de canales activos de información que promuevan conductas de prevención en temas como VIH y Sida. Así lo manifiesta un dirigente de una de estas organizaciones:

Yo creo que una de las cosas más importantes y por las cuales he sido activista y he trabajado es la educación, dar información necesaria y a tiempo, yo creo que una cosa muy importante es mantener a través de los medios de comunicación, en las instituciones educativas de todos los niveles que la enfermedad está presente, que la situación y el riesgo están presentes [...] Creo en la prevención a través de la información y de la educación, eso yo creo que es lo más importante. (Hombre de 42 años, docente)

Bajo esta perspectiva, se considera que el elemento más importante para desarrollar actitudes favorables para la incorporación de comportamientos de prevención es la educación, sin dejar a un lado la capacidad que tiene la población LGBTQ + para razonar y tomar decisiones favorables para el cuidado de su salud a partir de un conocimiento previo. Todo esto se traduce en una oportunidad y una exigencia para las instituciones educativas, pues se insiste en que es adecuado acoger la tarea preventiva en los jóvenes entre 15 y 18 años, contando con recursos educativos y personal cualificado, además de la posibilidad de implicar a los padres o personas responsables (GARCÍA-MARTíNEZ, 2005).

Frente a la información, se hizo evidente en las entrevistas que los involucrados están suficientemente informados de la necesidad de prevenir en ellos conductas de riesgo para adquirir el VIH, y sobre la manera como pueden hacer más seguros sus encuentros sexuales por medio del uso del preservativo o la abstinencia, como únicas opciones de mantenerse alejado de la infección 
por VIH. Además de los objetivos y efectos logrados por las campañas educativas de prevención en los comportamientos de riesgo, se destaca el desarrollo de la terapia antirretroviral para la infección por el VIH como uno de los sucesos más importantes de la medicina moderna, pues si bien ni mata ni cura el virus, reduce la morbi-mortalidad de quienes lo padecen. Entre los medicamentos e inhibidores que tratan el VIH, se ha destacado por su alta eficacia el TARVAE, evidenciándose en los pacientes, mejoras notables en el pronóstico y la calidad de vida; sin embargo, detrás de ello se han generado controversias en el campo clínico, ya que cada medicamento o inhibidor presenta resultados diversos, de acuerdo con las características metabólicas y hábitos de los pacientes (Julio MONTANER; John MELLORS, 2001; Paul SAX, 2001). El avance en estas terapias con medicamentos puede haber afectado la noción de peligrosidad del Sida y la adopción de comportamientos para evitar su contagio (Luz GONZÁLEZ-HERNÁNDEZ et al., 2014, p. 143-149). Sin embargo, aquellos que tienen la infección todavía presentan el virus en su cuerpo, y, a pesar de tomar la medicina, aún pueden transmitir el VIH a otras personas a través de las relaciones sexuales sin protección y de agujas compartidas (MEDLINEPLUS, 2015), adicionando incluso los efectos adversos y secundarios que, por sus características personales, estilo y hábitos de vida, pueden presentarse (InfoSIDA, 2016). Al respecto de los comportamientos de prevención, uno de los entrevistados manifestó:

Y la única forma de prevención es la utilización del preservativo. Yo digo que si el preservativo no existiera todo el mundo estaría infectado de VIH. Porque es la única forma, o no haciendo nada. Porque si no me quiero proteger simplemente tengo una relación sexual sin preservativo. (Hombre de 35 años, desempleado)

Entonces es eso, uno trata que los amigos nos prestemos condones (...) O sea, generalmente cargamos los condones. Entonces es la única manera de prevenir y si nos ha servido, porque la mayoría de nosotros no tenemos el VIH en este momento, y somos personas que pasamos los 30 años. (Hombre de 32 años, bacteriólogo)

Esas respuestas son presentadas desde una actitud racional que está fundamentada en su conocimiento, en la información recibida y en la incorporación de esa información al propio discurso de los HSH. Sin embargo, es importante preguntarse por el contexto de vida que rodea los encuentros de pareja de estas personas y que puede intervenir de forma funesta en la adopción de tales estilos de prevención permitiendo explicar en los HSH cómo la información de dicha prevención se relaciona o no con los actos de riesgo, o cómo esta información se interpreta para mantener cierto nivel de riesgo y no permitirse sobrepasarlo, tal es el caso de defender el uso de preservativos, más no de la disminución del número de compañeros sexuales, con lo que se exponen con cada encuentro a mayores probabilidades de contagio del virus del VIH.

En las entrevistas han aparecido factores del desarrollo afectivo individual, aspectos asociados a la forma como se relacionan con otras personas o con la manera como viven su propia orientación homo o bisexual que permiten entender la forma como se establece una relación con la información obtenida sobre el Sida (ESTRADA, 2004). Además de ello, ha de tenerse en cuenta el posible impacto mencionado anteriormente, a partir de la entrada en escena de los nuevos tratamientos retrovirales, más eficaces que los utilizados en décadas pasadas, lo que ha llegado a constituir una información que fundamenta la adopción de conductas de riesgo, considerando que la terapia retroviral brindará una adecuada calidad de vida ante una posible infección. En un estudio desarrollado en España con hombres que tienen sexo con hombres, se estableció que, debido a los retrovirales, los sujetos aceptaron conductas de riesgo, pasando de un 9.2\% al 19.4\% (Cinta FOLCH, Jordi CASABONA, Rafa MUÑOZ, Victoria GONZÁLEZ Y Katy ZARAGOZA, 2010, p. 40-46). Así mismo, en otros estudios se ha podido determinar que los HSH están menos preocupados por la prevención del VIH debido al desarrollo de las terapias retrovirales (Cinta FOCH; Gary MARKS; Anna ESTEVE; Katy ZARAGOZA; Rafa MUÑOZ; Jordi CASABONA, 2006, p. 227-242).

Sumado a ello, en varias de las entrevistas se encontró una ruptura entre la información que tienen los HSH sobre prevención y la manera como ésta es llevada a la cotidianidad de sus encuentros de pareja. Aunque se subraya la importancia de la utilización del preservativo, este imperativo pierde vigencia ante la posibilidad de un encuentro con un par donde se halle el placer y la posibilidad de establecer contactos afectivos. Esta búsqueda de la afectividad en los encuentros de pareja pareciera tratar de encontrar un lugar en una tendencia que puede permear el contexto latinoamericano, una tendencia que interroga la existencia del amor, y que prefiere la vivencia momentánea del placer sin compromiso alguno. Lo que sí pudiera establecerse es que se busca un intercambio, una ganancia (Edgar ACUÑA, 2008). Para el psicoanálisis, el deseo sexual constituye un motor permanente de búsqueda, donde el amor se esboza como una posibilidad, sin la cual, luego del encuentro sexual, se vuelve al estado inicial de soledad. De allí que puede entenderse cómo se accede a los encuentros sexuales como una forma de garantizar una satisfacción, que puede llevar a la resolución de carencias afectivas: 
Yo pienso, que por más conocimiento que se tenga sobre el VIH y aunque todos los homosexuales en este momento le tienen miedo al virus, es difícil manejar una situación sexual placentera, pues toca cuando se da la mínima oportunidad, cuando nadie está viendo, entonces es muy difícil que usted en esos momentos tenga todos los mecanismos para cuidarse, incluso psicológicos, pues a lo mejor uno en ese momento ni siquiera piensa en eso, porque está pensando, en pasar un momento bien. (E 16, p 5)

Si uno está consiente que va a ser por hoy y ya, se debería cuidar, uno muchas veces se afana por el placer y no por las consecuencias. (Hombre de 22 años, jefe de área)

Este afán por el encuentro placentero pone de manifiesto que los conocimientos son secundarios cuando del encuentro con el otro se trata, cuando bajo las circunstancias descritas previamente se establece la posibilidad de un momento sexual, que por supuesto está encadenado como tal a una serie de significados que son propios de los grupos HSH y que se concatenan con las vivencias propias de cada uno de sus ciclos vitales como sujetos y como grupo social. La importancia de lo sexual y lo afectivo, y la posibilidad de su coincidencia en un encuentro, alientan hacia la toma de decisiones que los permiten, pues ellos atraviesan la existencia del ser humano y definen la vivencia de la sexualidad (Paola ISAZA; Maria José URIBE, 2010):

Se parte del supuesto: 'una población educada, será una población que se protege', pero en la práctica no se da, vos podés tener una persona muy educada sobre el tema, pero que, a la hora de la verdad, cuando llega el momento de la relación, puede por el simple hecho de dejarse llevar por el placer, dejar a un lado todo lo que él sabía y meterse de lleno. (Hombre de 27 años, docente)

Las entrevistas dejan ver que existe una posición racional frente a la información que puede verse afectada cuando se reconoce que la circunstancia de encuentro ofrece una posibilidad única de vivencia placentera, y que esta vivencia no admite la reflexión, incluso que, si se piensa demasiado, puede que la oportunidad de ese encuentro placentero se pierda; en este sentido, las investigaciones señalan que cuándo se presenta mayor proximidad afectiva, se pierde la posibilidad de reflexión ante la prevención (GARCÍA-MARTíNEZ, 2005, p. 50-57).

Para finalizar, se hace pertinente la apreciación que los entrevistados presentaron sobre el papel pasivo que desarrollan ámbitos de formación primarios para los individuos, es decir, la escuela y la familia. En las entrevistas se hace énfasis en que la educación y la familia aportan poco a la formación y orientación en hábitos seguros para la prevención de los riesgos sexuales, situación que es agravada cuando se analiza el acceso a información y a otros ámbitos de educación en los servicios de salud, que se ven gravemente afectados por la intersección de la categoría de los comportamientos de la población LGBTQ + con los de la raza y la clase social, que pueden ahondar más la brecha entre conocimientos y acciones de prevención (Jaime MARTíN, 2013).

\section{Búsqueda de reconocimlento y afecto en los encuentros entre HSH}

Como seres humanos, antes que como hombres que hacen pareja con otros hombres, estas personas atienden al sentimiento de la necesidad de otro que los reconozca, los ame y proteja, siendo éstas también necesidades fundamentales para el desarrollo vital de toda su dimensión humana y afectiva.

La satisfacción de estas necesidades en el mundo adulto de un HSH es dirigida hacia su pareja, pero la construcción de la pareja homosexual está ligada directamente a una serie de directrices del "deber ser" y de los conceptos de pareja (Magdalena LEÓN, 1995, p. 483-513) que sirven de fundamento para el establecimiento de las parejas heterosexuales. Es allí donde se encuentra un primer obstáculo en la obtención de afecto, pues la pareja HSH hace crisis al intentar funcionar bajo unos preceptos que le son ajenos. Uno de los entrevistados deja entrever en su discurso la doble vertiente que constituye la pareja:

Construir pareja desde la dimensión homosexual no es fácil porque es que nosotros la estamos construyendo desde el mundo heterosexual, y el mundo machista, y el mundo patriarcal, $y$ entonces ese esquema no funciona para nosotros, nosotros tenemos que deconstruir demasiados esquemas y lo doloroso es que estamos trabajando es con los esquemas que nos da el mundo heterosexual, pero de todas maneras tener pareja para ser feliz vale la pena. (Hombre de 46 años, activista gay)

Las relaciones de pareja entre los HSH que accedieron a participar en esta investigación sucedieron característicamente más rápido que entre los heterosexuales que ellos conocían. Las entrevistas muestran cómo ellos se encuentran, se enamoran, hacen crisis y se desenamoran igual que las parejas heterosexuales, pero, unido a las características que rodean la vivencia de estas relaciones, la velocidad para tomar este camino y terminarlo es mucho más rápido. Los enamoramientos ocurren, por ejemplo, instantáneamente: "[...] conocí a ese tipo muy normalmente, me encontré con él, me lo presentaron y fue el flechazo" (Hombre de 20 años, estudiante). 
Para comprender esta situación, es importante tener en cuenta el escenario social en el que estas personas desarrollan la vivencia erótica y amorosa, que restringe sus posibilidades y expresiones, y que, aunque con algunos avances, niega las expresiones públicas de tales afectos por considerarlos impropios. Sin embargo, esta situación no debe considerarse como un universal inamovible, pues con los cambios sociales de las últimas décadas frente a la conducta de los grupos $L G B T Q+$, las parejas han tenido que recrear sus propias reglas y construir su propio formato para poder comunicarse y negociar su cotidianidad. Esto puede afirmarse con la expresión que algunos autores hacen sobre la vivencia de las parejas homosexuales en algunos contextos que les son más favorables, donde se presenta una "mayor aceptación de la pareja homosexual en la sociedad heterosexual" (Marina CASTAÑEDA, 2013, p. 56).

Estas relaciones inician generalmente con una atracción de orden sexual, pero, en la mayoría de los casos, los HSH presentan como punto de encuentro en sus discursos un gran anhelo de intercambio afectivo. Aunque se presentan frecuentemente relaciones riesgosas con personas incluso desconocidas, esta búsqueda pareciera sólo ser la estrategia para hallar en esos encuentros un reconocimiento del otro, y, tal vez, un lugar para la afectividad (Luis BONINO, 2000, p. 62); afectividad que probablemente ha sido expresada agresivamente por la familia al descubrir los intereses asociados con la población LGBTQ + de ese miembro, pues, en un contexto como el latinoamericano, los padres esperan que los varones se relacionen con mujeres, y que ellas hagan pareja con hombres, adoptando esta teoría como aquella que corresponde a la naturalidad en el orden de las cosas. Uno de los entrevistados describe el sentimiento que experimentó cuando comunicó su homosexualidad al grupo familiar: "Me sentí totalmente abandonado por mi familia [...] y ni una palabra, es muy doloroso que ellos sepan porque estoy sufriendo y no son capaces de preguntar" (Hombre de 44 años, terapeuta).

Ante el eventual rechazo del grupo familiar, el amor se consolida como aquel sentimiento que se dirige a aquel o a aquellos que sienten aceptación integral por todas las dimensiones que conforman a un sujeto. En este caso, un HSH ubica el amor en los lugares y en las personas que lo aceptan aún cuando han identificado su homosexualidad. Sin embargo, una parte de la sociedad no admite que este sentimiento pueda establecerse entre dos hombres, y, bajo este imperativo se hace más difícil exponer este tipo de afectividad, y, lógicamente, establecer relaciones de pareja formales que cuenten con el aval del otro. La homosexualidad pasa a ser un terreno privado (a diferencia del amor heterosexual, que puede establecerse en lo público), sin la existencia de figuras modelo, de arquetipos referenciales y de un estilo de vida aprobado culturalmente (Rodrigo ANDRÉS, 2000, p. 121-132).

Bajo estos condicionantes, y con las historias de vida representativas de los HSH de Medellín que fueron halladas en este estudio, se encuentra una brecha entre lo que la sociedad mitifica y admite como creencia frente a las conductas de los grupos $L G B T Q+$, y lo que los entrevistados refirieron acerca del amor en sus relaciones de pareja:

La gente cree que ser homosexual no incluye amar y eso es mentiras porque un homosexual puede llegar a amar mucho. A mi me duele que alguien no crea que alguien como yo es capaz de amar tanto, porque te aseguro que llegamos a amar tanto que yo soy capaz de dar mi vida por alguien que ame. Lo difícil es encontrarlo. O lo difícil es que sea compartido ese amor, pero si la gente supiera del amor que tenemos aquí adentro no nos criticarían tanto. (Hombre de 34 años, deportista)

Incluso llegan a afirmar una total dependencia de la relación con sus parejas, pues allí encuentran la afectividad que no han podido establecer en otras relaciones, lo que proporciona pistas sobre la dimensión que adquiere el encuentro con alguien cercano y de los riesgos que se está dispuesto a asumir, cuando éste está dispuesto a vivir una relación con compromisos emotivos:

Yo personalmente no soy dependiente ni de mis amigos, ni de mi familia, soy dependiente muy de mi relación, de mi pareja, y yo creo que me importa más lo que opine y desee mi pareja, a lo que decida mi mamá, mi papá, mi hermana o decidan mis amigos y en realidad no tengo amigos, porque igual solamente los tengo como conocidos y es por esa misma perspectiva, porque mis amigos no me van a dar lo que necesito. (Hombre de 29 años, diseñador)

Se puede apreciar entonces que las necesidades afectivas se encuentran presentes en los HSH como en cualquier ser humano, pero se manifiestan más urgentes por las dificultades para vivenciarlas de forma gratificante: "Mucha gente que está bajo el efecto de la depresión y llega alguien que le ofrece o le mendiga un poquito de amor, de pronto caen, es muy posible. O alguien que no tenga una autoestima adecuada" (Hombre de 42 años, docente).

Para muchos de los entrevistados estas conductas en la búsqueda de compañeros sexuales de forma apresurada responden a una manifestación que intenta negar la soledad que se ha engendrado con las vivencias de desarraigo que experimenta un HSH. De allí el aprovechamiento en el presente de cada posibilidad de encuentro afectivo. Se manifiesta entonces que la soledad se vislumbra como un horizonte posible para un $\mathrm{HSH}$, pues todas las dificultades y presiones hacen 
pensar que la compañía permanente, el amor, y la protección para estos personajes se hallan por fuera de sus posibilidades hacia el futuro. Esto abre una gama de interrogantes sobre las consecuencias que se deducen sobre la forma como estos sujetos se relacionan con las personas significativas en su vida, pues la búsqueda o el inicio de una relación de pareja están marcados desde el comienzo por el signo del desencuentro, que ante la perspectiva pareciera ser el desenlace único que tarde o temprano llegará.

\section{Conclusiones}

El Sida sigue estando vinculado metafóricamente a la población LGBTQ +, y específicamente a los grupos homosexuales, como consecuencia por una conducta no aceptada socialmente.

Los HSH sujetos de esta investigación tienen un nivel de información suficiente acerca del $\mathrm{VIH}$, sus acciones de riesgo no se basan en el desconocimiento. La información sobre el Sida, sus mecanismos de transmisión y de prevención y la posibilidad de la infección para cualquier sujeto fueron temas recurrentes durante las entrevistas. Pero, mientras que esta información podría fundamentar las conductas de prevención que se deriven de ella, lo encontrado corresponde a una división entre la información y los actos, actos que en muchos casos constituyen un riesgo inherente de contraer el virus del VIH y el Sida.

La unión de las carencias afectivas y la discriminación propician una sobrevaloración de los encuentros de pareja como soporte afectivo de la vida adulta; el afecto allí vivido se equipara al reconocimiento y la valoración de un ser humano que, en circunstancias similares, es valorado y legitimado por otro. Tal valoración también se ve afectada por otras condiciones que pueden aumentar la vulnerabilidad de algunas personas frente a las carencias afectivas, tales como la pobreza, la clase, la etnia o la raza.

La sobrevaloración del afecto permite pensar que la búsqueda constante de encuentros sexuales no sólo constituye un afán de satisfacción física, sino también la posibilidad de un intercambio de reconocimiento que sea sentido como afecto.

La intervención para disminuir los índices de la epidemia debe iniciarse en la escuela y en la familia, no sólo brindando información de la enfermedad para su prevención, sino además favoreciendo el respeto y la estimación por los que optan por diferentes maneras de vivir, para que se vinculen socialmente bajo unos parámetros de equidad, donde optar por la salud y utilizar la información para prevenir los riesgos sea válido.

La carencia afectiva fue encontrada característicamente en la mayoría de los informantes, y a partir del análisis sistemático de los discursos de esta categoría para la teoría desarrollada, puede afirmarse que esta carencia que se relaciona directamente con el rechazo de su homosexualidad por parte de sus figuras representativas de apego y protección, figuras que son asumidas por padres, cuidadores o familiares cercanos en etapas tempranas del desarrollo vital. El distanciamiento de estos personajes ocurre aunque la homosexualidad sea considerada permanente o circunstancial. Esta dificultad para sentirse reconocido y valorado desde sus primeros vínculos se une a la discriminación de los $\mathrm{HSH}$, que viene desde lo social como rechazo a la contravención, que significa una posición diferente a la heterosexual aceptada por la iglesia y por los sectores conservadores en lo que a valores morales se refiere.

\section{Agradecimientos}

A la estrategia de sostenibilidad CODI de la Universidad de Antioquia, por su apoyo para la realización del artículo.

\section{Referencias}

ACUÑA, Edgar. "Disertaciones psicoanalíticas y humanas sobre erotismo. Afectividad y amor". Revista de Psicoanálisis, Psicoterapia y Salud Mental, Salamanca, v. 1, n. 4. Disponible en: https:/ /studylib.es/doc/6450975/disertaciones-psicoanaliticas-y-humanas-sobre-erotismo. 2008. Acceso el 08/04/2017.

ANDRÉS, Rodrigo. "La homosexualidad masculina, el espacio cultural entre masculinidad y feminidad y preguntas ante una crisis". En: SEGARRA, Marta; CARABí, Angels. (Eds). Nuevas masculinidades. Barcelona: Icaria, 2000. p. 121-132.

BONINO, Luis. "Varones, género y salud mental: reconstruyendo la normalidad masculina". En: SEGARRA, Marta; CARABÍ, Angels. (Eds). Nuevas masculinidades. Barcelona: Icaria, 2000. p. 62.

CASTAÑEDA, Marina. La experiencia homosexual. Para comprender la homosexualidad desde dentro y desde fuera. Barcelona: Ediciones Paidós, 2013. p. 156. 
CENTRES FOR DISEASE CONTROL. "Pneumocystis pneumonia - Los Angeles". MMWR. Atlanta, v. 30, p. 250-2. Disponible en: https://www.cdc.gov/mmwr/preview/mmwrhtml/june_5.htm. 1981. Acceso el 13/04/2017.

CHIRINOS, Jesús; BARDALES, Olga; SEGURA, María. "Las relaciones coitales y la percepción de riesgo de adquirir ETS/SIDA en adultos jóvenes varones de Lima, Perú". Cad. Saúde Pública [En línea]. Rio de Janeiro, 2006, v. 22, n. 1, p. 79-85. Disponible em: http://www.Sidastudi.org/resources/ inmagic-img/dd1346.pdf. Acceso el 18/04/2017.

COLL-PLANAS, Gerard; CRUELLS, Marta. "La puesta en práctica de la interseccionalidad política: el caso de las políticas LGTB en Cataluña". Revista Española de Ciencia Política [En línea]. Logroño, 2013, n.31, pp. 153-172. Disponible en: https://recyt.fecyt.es/index.php/recp/article/view/37578. Acceso el 15/03/2017.

CORBIN, Juliet; STRAUSS, Anselm. Bases de la investigación cualitativa. Técnicas y procedimientos para desarrollar la teoría fundamentada. Medellín: Editorial Universidad de Antioquia, 2002.

DE LA CUESTA, Carmen. Interaccionismo-interacción-teoría fundada. Medellín: Fundación Luis Amigó, 1999.

DIRECCIÓN SECCIONAL DE ANTIOQUIA. Eventos de interés en salud pública por subregiones y municipios. Antioquia 2007 - 2017. Medellín: La Dirección. Disponible en: https://www.dssa.gov.co/ index.php/estadisticas/eventos-en-salud-publica/item/71-eventos-de-interes-en-salud-publicapor-subregiones-y-municipios-antioquia-2007-2014. 2011. Acceso el 25/03/2017.

ESTRADA, John. "La infección por VIH-Sida entre hombres que tienen sexo con hombres en América Latina". Rev. Fac. Nal. Salud Pública, Medellín, v. 22, n. 1, p. 118, 2004.

FOLCH, Cinta; MARKS, Gary; ESTEVE, Anna; ZARAGOZA, Katy; MUÑOZ, Rafa; CASABONA, Jordi. "Factors Associated with Unprotected Sexual Intercourse with Steady Male, Casual Male, and Female Partners Among Men Who Have Sex With Men in Barcelona, Spain". AIDS Education and Prevention, New York, v. 18, n. 3, p. 227-242. Disponible en: https://guilfordjournals.com/doi/10.1521/aeap.2006.18.3.227. DOI: 10.1521/aeap.2006.18.3.227, 2006. Acceso el 10/02/2017.

FOLCH, Cinta; CASABONA, Jordi; MUÑOZ, Rafa; GONZÁLEZ, Victoria; ZARAGOZA, Katy. "Incremento en la prevalencia del $\mathrm{VIH}$ y en las conductas de riesgo asociadas en hombres que tienen sexo con hombres: 12 años de encuestas de vigilancia conductual en Cataluña". Gac. Sanit., Barcelona, v. 24, n. 1, p. 40-46. Disponible en: http://ac.els-cdn.com/S021391110900329X/1-s2.0-S0213911109 00329X-main.pdf? tid $=c 8842$ b64-326d-1 1 e6-a73b-00000aacb35f\&acdnat $=1465935957$ 6f9b 83d90c3958b1 10c-2591ac0e99edc. 2010. ISSN 0213-9111. DOI: 10.1016/j.gaceta.2009.06.010. Acceso el 20/03/2017.

GARCÍA-MARTíNEZ, Alfonso. "Educación y prevención del SIDA". Anales de Psicología, Murcia, v. 21, n. 1, p. 50-57, junio. 2005.

GOETZ, Judith; LECOMPTE, Margaret. Etnografía y Diseño cualitativo en Investigación educativa. Madrid: ED. Morata, Colección Pedagogía Manuales S.A., 1998

GONZÁLEZ-HERNÁNDEZ, LUz; LLAMAS-COVARRUBIAS, Mara; GONZÁLEZ-VÁZQUEZ, Edith; CAMPOS-LOZA, Ariel; ARCE-ROSAS, Jorge; MERCADO-NUÑEZ, Emmanuel; SORIA-RODRÍGUEZ, Raul; GARCÍA-CASTRO, José; ANDRADE-VILLANUEVA, Jaime. "Nuevas terapias antirretrovirales en la infección por VIH". Revista Médica MD, Guadalajara, v. 5, n. 3, p.143-149, 2014.

GUAJARDO, Gabriel. "Contexto sociocultural del sexo entre varones". En: CÁCERES, Carlos; PECHENY, Mario; VERIANO, Terto. (Eds). SIDA y sexo entre hombres en América Latina: vulnerabilidades, fortalezas, y propuestas para la acción Perspectivas y reflexiones desde la salud pública, las ciencias sociales y el activismo. Perú: UPCH/ONUSIDA, 2002. p. 57-79.

InfoSIDA. Efectos secundarios de los medicamentos contra el VIH. Maryland: National Library of Medicine, NLM. Disponible en: https://infosida.nih.gov/understanding-hiv-aids/fact-sheets/22/63/ medicamentos-contra-el-vih-y-sus-efectos-secundarios. Acceso el 20/03/201 7.

ISAZA, Paola; URIBE, Maria José. Impacto de las trayectorias sexuales y afectivas en la relación de pareja durante el noviazgo. Trabajo de Grado. Facultad de Psicología. Bogotá: Pontificia Universidad Javeriana, 2010. 
LEÓN, Magdalena. "Familia y género: encuentros y desencuentros. Un análisis desde la sociología". En: Memorias del Primer Congreso Latinoamericano de Familia Siglo XXI. Medellín: Alcaldía de Medellín, 1995, p. 483-513.

LLAMAS, Ricardo. Teoría torcida. Prejuicios y discursos en torno a la homosexualidad. Madrid: Siglo Veintiuno de España Editores, 1998.

MARTÍN, Jaime. Diversidad sexual, discriminación y pobreza frente al acceso a la salud pública: demandas de la comunidad TLGBI en Bolivia, Colombia, Ecuador y Perú. Buenos Aires: CLACSO. Disponible en: http://biblioteca.clacso.edu.ar/clacso/clacso-crop/201308291 15928/Diversidad Sexual.pdf. 2013. Acceso el 12/12/2016.

MEDLINEPLUS. Medicinas para el VIH y el sida. Rockville Pike: U.S. National Library of Medicine. Disponible en: https://www.nlm.nih.gov/medlineplus/spanish/hivaidsmedicines.html. 2015. Acceso el 18/02/2017.

MINISTERIO DE LA PROTECCIÓN SOCIAL. Informe UNGASS 2010. Seguimiento de la Declaración de Compromiso sobre El virus que produce el SIDA. Bogotá: El Ministerio. Disponible en: https:// www.minsalud.gov.co/salud/Documents/2_abril2012_final_UNGASS_COLOMBIA.pdf. 2012. Acceso 18/02/2017.

MINISTERIO DE LA PROTECCIÓN SOCIAL; ORGANIZACIÓN PANAMERICANA DE LA SALUD. Boletín Epidemiológico. Situación de El virus que produce el SIDA. en Colombia. Bogotá: El Ministerio, OPS, 2013.

MONTANER, Julio; MELLORS, John. "Antiretroviral therapy for previously treated patients" (editorial). $N$ Engl J Med, v. 345, n. 6, p. 452, 2001.

ONUSIDA. Infección por VIH-Sida en Colombia: aspectos fundamentales, respuesta nacional y situación actual. Santafé de Bogotá: ONUSIDA, 1999.

ORGANIZACIÓN DE ESTADOS AMERICANOS (OEA). Formas y contextos de la violencia contra personas lesbianas, gays, bisexuales, trans e intersex. Washington: CIDH. Disponible en: http://www.oas.org/ es/cidh/multimedia/2015/violencia-lgbti/formas-violencia-lgbti.html. 2015. Acceso 18/02/2017.

ORGANIZACIÓN PANAMERICANA DE LA SALUD, ORGANIZACIÓN MUNDIAL DE LA SALUD, ONUSIDA. VIH y Sida en las Américas. Una epidemia multifacética. Washington: OPS, OMS, ONUSIDA, 2001.

ORGANIZACIÓN MUNDIAL DE LA SALUD, ORGANIZACIÓN PANAMERICANA DE LA SALUD, ONUSIDA. Prevencioin de la infeccioin por el VIH bajo la lupa. Un anailisis desde la perspectiva del sector de la salud en Ameìrica Latina y el Caribe [Internet]. Washington, D.C.: OPS, ONUSIDA; 2017 [citado 03 jul 2019]. Disponible en: https://www.paho.org/prevencion-vih-la-lupa-2017/

PISANI, Elizabeth; BROWN, Tim; SAIDEL, Tobi; REHLE, Thomas y CARAËL, Michel. Recopilación de datos sobre el comportamiento necesarios para los programas nacionales de VIH, Sida e infecciones de transmisión sexual. Ginebra: IMPACT, FHI, ONUSIDA, 2002.

PROFAMILIA. Encuesta Nacional de Demografía y Salud 2005. Medellín: PROFAMILIA. Disponible en: http://profamilia.org.co/docs/ENDS\%202005.pdf. 2006. Acceso 13/11/2016.

REPÚBLICA DE COLOMBIA. MINISTERIO DE SALUD. Resolución 8430 de 1993: por la cual se establecen las normas científicas, técnicas y administrativas para la investigación en salud. Bogotá: Ministerio de Salud, 1993.

SAX, Paul. "Opportunistic infections in HIV disease: down but not out". Infect Dis Clin North Am, Bethesda, v. 15, n. 2, p. 433-455, 2001.

SERVICIO SECCIONAL DE SALUD DE ANTIOQUIA. Significado del Sida y la infección por VIH para grupos expuestos a un mayor riesgo de infección. Medellín: Servicio Seccional, 1993.

SONTAG, Susan. El Sida y sus metáforas. Barcelona: Muchnik Editores, 1989.

TORO, José. "Vulnerabilidad de hombres gays y hombres que tienen sexo con hombres (HSH) frente a la epidemia del El virus que produce el SIDA. en América Latina: La otra historia de la masculinidad". En: CÁCERES, Carlos; PECHENY, Mario; VERIANO, Terto. (Eds). SIDA y sexo entre hombres en América Latina: vulnerabilidades, fortalezas, y propuestas para la acción Perspectivas y reflexiones desde la salud pública, las ciencias sociales y el activismo. Perú: UPCH/ONUSIDA, 2002. p. 81-102. 
UNAIDS. UNAIDS data 2018 [Internet]. Génova: UNAIDS, 2018. [citado 03 jul 2019]. Disponible en: https://www.unaids.org/sites/default/files/media_asset/unaids-data-2018_en.pdf

VINACCIA, Stefano; QUICENO, Japcy; GAVIRIA, Ana; SOTO, Ana; GIL, María; BALLESTER, Rafael. "Conductas Sexuales de Riesgo para la Infección por El virus que produce el SIDA en Adolescentes Colombianos". Ter Psico, Santiago, v. 25, n. 1, p. 39-50. Disponible en: http://www.scielo.cl/ scielo.php?script =sci_arttext\&pid =s0718-48082007000100003\&lng=es\&nrm=iso. 2007. ISSN 0718-4808. DOI: 10.4067/S0718-48082007000100003. Acceso el 15/04/2017.

Isabel Cristina Posada Zapata (isabel.posada@udea.edu.co) es Psicóloga, Magíster en Salud Pública. Candidata a Doctora en Ciencias Sociales Niñez y Juventud. Profesora Asociada Universidad de Antioquia, Medellín, Antioquia, Colombia. 050001.

Carlos Enrique Yepes Delgado (carlos.yepes@udea.edu.co) es Médico y cirujano. Especialista en Administración. Magíster en Salud Pública. Doctor en Epidemiología. Profesor titular Facultad de Medicina. Universidad de Antioquia. Médico epidemiólogo Hospital Pablo Tobón Uribe. Medellín, Antioquia, Colombia.

Lina Marcela Patiño Olarte (linamarce875@gmail.com) es Profesional en Gerencia de Sistemas de Información en Salud, Especialista en Estadística y en Gestión de Información y Bases de datos. Coordinadora Fondo Editorial IUE y Editora Asistente Revista Facultad Nacional de Salud Pública.

\section{COMO CITAR ESTE ARTÍCULO, DE ACUERDO CON LAS NORMAS DE LA REVISTA:}

ZAPATA, Isabel Cristina Posada; DELGADO, Carlos Enrique Yepes; OLARTE, Lina Marcela Patiño. "Amor, riesgo y Sida: hombres que tienen sexo con hombres". Revista Estudos Feministas, Florianópolis, v. 28, n. 1, e50443, 2020.

\section{CONTRIBUCIÓN DE AUTORÍA}

Isabel Posada: concepción, recolección de datos y análisis de datos, elaboración del manuscrito, redacción, discusión de resultados.

Carlos Yepes: Apoyo para análisis de los datos y para la discusión de resultados.

Lina Patiño: Apoyo para la elaboración del manuscrito y redacción de los resultados.

\section{FINANCIACIÓN}

A la estrategia de sostenibilidad CODI de la Universidad de Antioquia, por su apoyo para la realización del artículo.

\section{CONSENTIMIENTO DE USO DE IMAGEM}

No aplicable

APROBACIÓN DE COMITÉ DE ÉTICA EN INVESTIGACIÓN

No aplicable

\section{CONFLICTO DE INTERESES}

No aplicable

\section{LICENCIA DE USO}

Este artículo está licenciado bajo la Licencia Creative Commons CC-BY Internacional. Con esta licencia se puede compartir, adaptar, crear material para cualquier objetivo, siempre que se le atribuya la autoría.

\section{HISTORIAL}

Recibido el 07/05/2017

Presentado nuevamente el 08/04/2019

Presentado nuevamente el 05/07/2019

Aprobado el 25/07/2019 